\title{
A designação de violência em dicionários de língua
}

\author{
Raquel Ribeiro Moreira (UTFPR) ${ }^{1}$
}

Resumo: A relação entre um referente e um conceito permeia nossa análise sobre a noção de violência neste trabalho. Tratada principalmente como característica intencional e individual nos dicionários de língua por nós analisados, a violência retrata o modo estático e homogêneo como os diferentes dicionários trabalham com as relações de sentido. Fundamentados na Análise de discurso de linha francesa, observamos que, diferentemente do que encontramos nos dicionários, a heterogeneidade do conceito de violência marca a discrepância entre o pensamento e o real discursivo, porque coloca a violência a partir de posições inscritas em diferentes FDs.

Palavras-chave: violência, dicionário, sentido, referência, análise do discurso.

\section{Considerações iniciais}

O que significa a violência? Esse é um conceito objetivo, independente, monossêmico? Os sujeitos envolvidos em/na violência são invariavelmente agressores e/ou vítimas, dotados de intenção e vontade? A violência é constitutiva da natureza dos indivíduos; prejudica e/ou controla a sociedade; somente será combatida com "resgates" ou "injeções" morais, éticas, educacionais, sociais...? Todos esses questionamentos, que aparecem na maioria das vezes como asserções, e por isso integram os mais diversos dicionários das mais diversas áreas, revelam-nos a dificuldade de se tentar cercear os sentidos, na qual se preze unicamente a fixidez do referente e a simetria entre este e um conceito.

Dizemos difícil, porque nos parece não existir uma relação simétrica entre um referente e um conceito. O referente não tem fixidez. Do mesmo modo, a relação assimétrica existente não é uma questão de subjetividade individual, mas histórica, pois se constrói através do modo como o sujeito se relaciona sócio-historicamente com o objeto. Assim, podemos dizer que a referência em $\mathrm{AD}$ depende da inscrição do sujeito em uma ordem simbólica e histórica, e não de uma operacionalização da língua e nem da vontade subjetiva dos indivíduos.

De forma diversa de teorias formalistas-logicistas, na teoria marxista - na qual a $\mathrm{AD}$ se inscreve - a base linguística não tem fixidez, o que resulta na

\footnotetext{
${ }^{1}$ Doutora em Estudos da Linguagem pela Universidade Federal do Rio Grande do Sul (UFRGS). E-mail: raquelutfpr@gmail.com
} 
autonomia apenas relativa da língua. Se o signo é motivado histórica e socialmente, ou seja, se é no momento em que o signo se insere na ordem histórica e simbólica que se instaura o sentido, não há como falar em fixidez da língua ou reflexo direto entre o homem e o mundo. A capacidade humana de representar objetivamente o mundo real - orgânico e não o ideal - é uma ficção, porque o "reflexo" não é direto nem transparente, pois a matéria é incondicionalmente transformada e o mundo regulado por processos de mutação da matéria. Assim, o saber humano sobre a condição do sentido somente se produz a partir da reflexão sobre as condições que permitem ou que atuam sobre a transformação da matéria, sejam tais condições externas ou internas. Daí não haver interação objetiva nem estática entre os objetos e o mundo. Não há estaticidade do signo, mas mobilidade permanente do sentido. A ordem do real somente se reflete como uma ordem ideológica, ou seja, uma ordem que existe, mas que se embasa em uma materialidade em permanente transformação e que se dá em consequência da tomada de consciência pelo sujeito de suas próprias condições de existência. Idealmente, ou seja, apartado das condições históricas e simbólicas, dos modos de produção de existência e do modo como é facultada a reflexão sobre as relações desempenhadas e os papéis cumpridos nas relações de produção, não há sujeitos nem processos discursivos, somente signos e indivíduos.

E é justamente na eminência de se poder procurar em que lugar o conceito de violência se encontra nos dicionários - se é um conceito que tem como base um referente estático ou se é um referente que possui ancoragem na ordem do real - que analisaremos os verbetes a seguir.

\section{Os dicionários e a violência}

Existem alguns "usos" linguísticos que servem como instrumentos de regulação da língua. Essa "função" pode ser encontrada nos compêndios e manuais linguísticos, nos livros didáticos em geral, nos currículos escolares e nos dicionários. Tendo em vista o dicionário, por ser um instrumento de consulta, é considerado incontestável: sem margem de erro e, por isso, sem restrições de uso.

Contudo, se verificarmos os dicionários de diversas áreas, com o intuito de observar como essas diferentes áreas conceituam a violência, é possível constatar que os dicionários não se colocam como meros instrumentos de consulta, mas como porta-vozes que sintetizam e normatizam saberes específicos, nos quais não há contradição, não pairando, portanto, sobre si, quaisquer dúvidas ou interdições. Eles se caracterizam como lugares do saber estabilizado, completo e funcional, em que os sentidos são exauridos na conceituação temática estipulada. Este exaurir - no qual se julga constar até mesmo os sentidos margeados - é uma forma de "comportar" a palavra, quer 
dizer, negar-lhe a polissemia e/ou a ambiguidade, enfim, de domesticar-lhe o sentido. Se o espaço do/para o sentido aparenta ser múltiplo, ele, todavia, se quer totalizante e controlador. É nesse sentido que Oliveira (2006), citando Auroux, nos diz que os dicionários são definidos como tecnologias de gramatização, pois:

Ao descrever as línguas, os dicionários (e as gramáticas) produzem um prolongamento do saber linguístico do falante, que não apenas o estende, mas o transforma. Transformação esta que é política, na medida em que se dá como a produção de uma normatividade sobre a língua (AUROUX, 1992 apud OLIVEIRA, 2006, p. 18).

Essa transformação que normatiza é diferente daquela mutação de que falávamos anteriormente. Se esta última garante o permanente movimento dos sentidos, aquela é o mecanismo autoritário que converte o real da língua em real linguístico (reforçado pelos processos de higienização e estigmatização linguísticas). Assim, os processos discursivos se esvaziam de sua práxis e se transformam em vocábulos/verbetes, nos quais se tenta apagar qualquer vestígio do sujeito (constituindo aquilo que Pêcheux (1997) chama de processo sem sujeito - ilusão de neutralidade e objetividade da língua) na perspectiva de universalização das definições. Naturalizam-se, desse modo, determinadas referências que projetarão (de uma forma ilusória, é claro) as mais diversas relações da língua com as coisas do mundo; é por isso, portanto, que os dicionários estão em constante revisão, com a retirada dos significados em desuso e a inserção dos "novos" dizeres do/sobre o mundo, no eterno movimento de atualização e eficiência.

Repetimos diversas vezes o caráter ilusório dessa constituição do dicionário, porque não compartilhamos da visão estruturalista de apagamento do político e do histórico aí. Ao contrário, pois, se todo dizer é sempre proferido (pensado/silenciado/reproduzido ....) por um sujeito, ou seja, por um indivíduo interpelado ideologicamente, e se esse dizer se inscreve em regiões do interdiscurso onde há divisão, dominância e movência, então esse dizer só pode ser histórico e político. Não um político arbitrário e impositor, mas um político que trabalha sobre a divisão ideológica dos sentidos. E também não é um histórico como evolução, o que justifica as revisões nos dicionários, retirando-se os "arcaísmos" e inserindo-se os "neologismos", mas o histórico como memória interdiscursiva, que constitui o processo discursivo e faz trabalhar os sentidos. Desse modo, trabalhar o dicionário não é lidar com um instrumento universalizante, com predomínio do efeito referencial da linguagem, mas com um lugar discursivo em que a polissemia e a ressemantização produzem movimentos nos espaços de enunciação da palavra. Para Oliveira (2006), são esses movimentos que conduzem à mudança: 
Todos esses movimentos, que se dão sob o modo de divisões e redivisões dos ou nos espaços de enunciação em que se inscreve a designação da palavra [...], constituem o movimento próprio do político na normatividade das definições lexicográficas. Movimento este que está ligado ao caráter histórico do dizer e, assim, a divisões ideológicas presentes em nossa sociedade (Ibid., p. 117).

É sob esse prisma que analisaremos neste artigo alguns verbetes sobre violência em dicionários de língua, com o intuito de observar a heterogeneidade do conceito. Para tanto, nossa análise tratará do que é violência e suas formas de expressão.

\section{O que é violência e suas formas de expressão}

Oliveira (2006), em seu livro Cidadania: história e política de uma palavra, explica que os verbetes apresentam uma estrutura particular, composta pela palavra-entrada e a definição. A palavra-entrada é o ponto de deriva sobre o qual a definição se apoia; essa é a relação fundamental pela qual se constrói a textualidade do verbete. Essa estrutura é igual em todos os dicionários e até em alguns manuais de áreas específicas. O que diverge em um dicionário de língua e um sociológico, por exemplo, é justamente o modo de construção de sua textualidade. A nossa palavra-entrada é Violência, é nela que nos apoiaremos para verificar os sentidos moventes que daí se constroem nas definições, definições essas que perpassam caminhos bastante diferentes nos diversos dicionários: de determinações designativas de um nome nos dicionários de língua a descrições pormenorizadas e analisadas do conceito e de suas interações nos dicionários sociológicos.

Como rota de percurso, vamos analisar o que é a violência e suas formas nos seguintes dicionários: Novo dicionário Etimológico de Língua Portuguesa - Rodrigo Fontinha (s/d); Dicionário Houaiss de Língua Portuguesa - Houaiss, Villar e Franco (2004); Novo Aurélio século XXI: o dicionário da língua portuguesa - Aurélio Buarque de Holanda Ferreira (1999).

Enfatizamos que, em função dos objetivos específicos, não iremos transcrever todos os verbetes na íntegra, mas somente as sequências discursivas que atendam aos nossos objetivos.

\section{Dicionários de língua}

O primeiro dicionário a ser examinado é o de Rodrigo Fontinha. Segundo ele, violência é: 
"Violência. s.f (Lat. Violentia (m))- Qualidade de violento; acção ou resultado da aç̧ão de violentar ou violentar-se; impeto veemente nas ações; força com que se pretende obrigar uma pessoa a fazer aquilo que ela não quer; acto violento; abuso da força e do poder; opressão; grande impulso; veemência, impetuosidade; coação; constrangimento".

Ao analisarmos a definição, parece-nos que nesse dicionário a prática da violência se dá em um fazer, uma ação centrada em indivíduos que usam de força (física ou no exercício de algum poder: abuso, opressão) para causar algum dano a outros ou a si mesmo. Ação que pode ser sempre voluntária, uma vez que se age com ímpeto, vontade, e na qual podem surgir consequências: ação ou resultado da ação de violentar, ou seja, essa violência pode não ser pontual e delimitada, mas imprescindivelmente deriva de um ato. Em seguida, observamos que a primeira definição que temos é a de violência como qualidade do que é violento - fato que vai repetir-se nos três dicionários de língua analisados:

Dicionário Houais: "Violência. s.f. Qualidade do que é violento".

Novo Aurélio século XXI: "Violência. [Do lat. violentia] S.f. 1. Qualidade de violento. 2. Ato violento. 3. Ato de violentar. 4. Jur. Constrangimento físico ou moral; uso da força; coação".

Aliás, não somente a primeira estrutura é idêntica nos três dicionários, como praticamente toda a definição: a violência é o uso da força de alguém para alguém com objetivo de dano. Retomando o primeiro ponto, e considerando a primazia do conceito de violento na caracterização de violência, vejamos como se dá uma definição do adjetivo. Para isso, recorramos ao Aurélio:

"Que age com impeto. Impetuoso. Que se exerce com força. Agitado, tumultuoso. Irascivel, irritadiço. Intenso, veemente. Em que se faz uso da força bruta. Contrário ao direito e à justiça”.

Deixando de lado, para não nos tornarmos repetitivos, o exercício da força como característica tanto da violência quanto do violento, vemos elementos diferenciados nesse verbete, como, por exemplo, a impetuosidade, a irritação, a agitação, a intensidade e a veemência. Se a violência é uma qualidade do violento, e se ser violento é possuir qualquer uma dessas características, então alguém com ímpeto, irritado, agitado, intenso e/ou veemente é violento e, portanto, está praticando uma violência? Certamente nos dirão que a questão não é tão simples assim, que é preciso ver que essas características comportam outras práticas, que constroem outros sentidos, que apontam para outras situações sócio-históricas... Do que nós responderemos 
afirmativamente. Daí a impossibilidade de cercar os sentidos em verbetes. Além do que, mesmo considerando essas outras possibilidades, como responder a questões como: um agitado grupo de alunos que grita com veemência contra o processo cada vez mais concentrado de sucateamento da universidade pública está praticando um ato violento? Violento contra quem? Ou ainda, um impetuoso policial que avança sobre uma tumultuada ocupação de sem-terras em uma fazenda privada e improdutiva, fazendo seu trabalho de forma intensa, é violento? Quem, nessa situação, sofre, ou melhor, não sofre violência? Há também, no verbete, a citação de violento como quem se faz contrário ao direito e à justiça. Nesse sentido, e levando-se em conta os exemplos por nós trazidos acima, é favorável à justiça aquele que luta por seus direitos ou aquele que se acomoda aos preceitos legais erigidos por uma pequena parte da sociedade? Qual desses dois sujeitos é mais violentador/violentado?

Tais questões nos apontam para algo que os dicionários expurgam com o fim de manter sua postura de inquestionáveis: o equívoco. São justamente esses pontos de equívoco, nos quais se inscreve a polissemia, que nos mostram a falha na universalidade pretendida nesses materiais. Não é possível assumir designações objetivas e transparentes em uma língua que, viva, determina-se no cruzamento dos discursos em jogo e no funcionamento do histórico e do político nos dizeres. Os questionamentos vistos acima habilitam o jogo discursivo e, portanto, destoam das definições dos verbetes.

Como vínhamos dizendo, os três dicionários de língua analisados comportam basicamente a mesma definição de violência, contudo, verificamos diferenças entre eles que merecem ser analisadas.

Se o dicionário de Fontinha trazia a ação através do uso da força como definição de violência, o dicionário Aurélio não inova em absoluto, ao contrário, suprime especificações, rotulando-as sob o substantivo ato: ato violento, ato de violentar, numa clara tentativa de definir a violência em correspondência com o adjetivo violento. $\mathrm{O}$ único diferencial é que este, ao trazer a noção de constrangimento, recorre à área jurídica para denominar as duas formas de constrangimento possíveis: física e moral, mas que somente retomam, e de forma ainda mais limitada, aquilo que Fontinha havia especificado sobre o abuso da força e do poder.

O dicionário que mais se diferencia, mas que ainda assim traz a ação e a força como ideias mestras da constituição da violência, é o Houaiss. Vejamos o verbete na íntegra:

"Violência. s.f. (sxiv cf. Fich IVPM) 1. qualidade do que é violento $<a$ v. da guerra $>2$. ação ou efeito de violentar, de empregar força física (contra alguém ou algo) ou intimidação moral contra (alguém); ato violento, crueldade, força $<$ sem lei, a polícia pratica violências contra o individuo $><0$ gigante derrubou a porta com sua $v .>3$. exercício injusto on 
discricionário, ger. ilegal, de força ou de poder $<v$. de um golpe de Estado $>3.1$ cerceamento da justiça e do direito, coação, opressão, tirania $<$ viver num regime de $v .>4$. força súbita que se faz sentir com intensidade; fúria, veemência $<a v$. de um furacão $><u m a v$. de sentimentos $><a v$. de sua linguagem $>5$. dano causado por uma distorção ou alteração não autorizada $<v$. da censura pouco esclarecida $>6$. o gênio irascivel de quem se encoleriza facilmente, e o demonstra com palavras el ou ações <temia a v. com que o avô recebia tais noticias $>7$. JUR. Constrangimento físico ou moral exercido sobre alguém, para obrigá-lo a submeter-se à vontade de outrem; coação - V.arbitrária DIR. PEN. crime que consiste em praticar a violência, no exercício de uma função ou a pretexto de exercê-la. V.carnal DIR.PEN. relação sexual mantida com uma mulher mediante a utilização de força; estupro. Q ETIM. Lat. violent ${ }^{\text {la }}$, ae'violência, impetuosidade (do vento), ardor (do sol), arrebatamento, caráter violento, ferocidade, sanha; rigor, severidade, der.de violentus, a, um' impetuoso, furioso, arrebatado $\operatorname{bINV}$ AR ver sinonimia de fúria - ANT brandura, docura".

Contemplamos, na definição de Houaiss, a repetição na caracterização do ato violento, no uso da força física e do poder, da coação e da intimidação moral como elementos designativos da violência. Contudo, essas designações, ao serem acompanhadas de exemplos, fazem um processo duplo de alargamento e estreitamento das definições. De alargamentos, pois, com os exemplos, pode-se tratar de fatos não abarcados nos verbetes anteriores - a violência da guerra, de um golpe de estado, de um regime tirânico - e que desmistificam a ação da violência como um ato isolado de indivíduo(s) para indivíduo(s). Por outro lado, em exemplos como a fúria de um furacão, de um amor, de um gigante (sic) e de um avô encolerizado, descola-se a violência de seu caráter político e social, encaixando-a em uma perspectiva subjetiva, na qual a violência é vista exclusivamente como uma força interna a algo, ao ser humano ou a um elemento da natureza, que 'brota' ao ser instigada, sem relação específica aos elementos de poder e submissão apontados no mesmo verbete.

E não são somente os exemplos que apontam para a miscelânea conceitual dos sentidos de violência; para tentar garantir a "totalidade" de acepções que um dicionário deve conter - dentro de uma concepção universalizante, isto é, de uso indiscriminado para qualquer fim - acrescenta-se às definições já dadas uma voz de autoridade que busca reforçar o viés de que os dicionários são incontestáveis: o discurso jurídico. E não é só ele, a etimologia também constitui arcabouço de reconhecimento, é ela que reflete a gênese (já que retoma as palavras em latim: a origem) de força, impetuosidade e fúria da violência - e se é gênese é a mais pura expressão da verdade. Mas é no/do Direito mesmo que se tem o reconhecimento de um saber verdadeiro, de definições que extrapolam a margem simbólica e ganham uma materialidade legal: o constrangimento físico ou moral que se diluem ou na prática arbitrária do poder ou no abuso físico (e aqui se encaixa também a violência carnal) e 
psicológico de alguém para alguém. Novamente vemos a noção de violência como ato individual retomada, que não é somente atualizada pelo discurso jurídico, mas legitimada. Se esse é o "canal de tratamento" da violência, e se essa é tratada aí como uma prática de indivíduos, portanto é desse modo que ela deve ser entendida. Então, se nesse verbete a violência é concebida como uma prática de indivíduos, ela deve ser interna ao sujeito, o que lhe reforça as concepções imanentistas apontadas acima, mas que, entretanto, nos causam certo estranhamento quando nos deparamos com a definição 5: "dano causado por uma distorção on alteração não autorizada $<v$. da censura pouco esclarecida $>$ ".

Não tanto pela definição, que ainda pode trazer uma perspectiva individualista: uma apropriação acadêmica, um plágio, a adulteração de documentos..., mas por seu exemplo. A censura é um ato político, um processo discursivo, e como tal ele vem impregnado de posicionamentos ideológicos diferentes e divergentes que extrapolam em muito a esfera individual. Não se trata mais de como o indivíduo lida com a censura, mas o que ela acarreta para as relações em sociedade e para a vida do indivíduo como membro dessa sociedade. Ao se falar de censura, não há mais como acorrentar a violência a atos isolados de alguém para alguém.

\section{Considerações finais}

Esse "vai-e-vem" de pontos de ancoragem não nos parece mostrar a heterogeneidade do conceito de violência, mas a postura do dicionário (ou dicionários de uma forma geral) de "linearizar" discursos complexos e polissêmicos a partir de trechos fragmentados e descontextualizados, tentando determinar, através da referência, aquilo que poderíamos chamar de "discursivização", ou seja, processos anteriores e exteriores que se interrelacionam com as forças históricas que dirigem a existência dos sujeitos e com o campo das práticas sociais. Se na Análise de Discurso, a heterogeneidade do conceito de violência marca a discrepância entre o pensamento e o real discursivo, porque coloca a violência a partir de posições inscritas em diferentes FDs e que, portanto, significa diferentemente; nos dicionários de língua por nós analisados, percebe-se a constituição do sentido, ou melhor, da significação, como o elenco de designações diferentes, mas que são, sempre, versões, possibilidades da mesma "referência", homogênea e universal. Desse modo, torna-se, a nós, inconteste a desconstrução da visão ingênua e teoricamente parcial de que os dicionários são arcabouços holísticos e heterogêneos de sentidos, porque não são, já que, ao contrário de apontarem para as transformações e derivas, eles apresentam a estagnação e homogeneização dos sentidos.

Castoriadis (1982) afirma que não podemos compreender uma sociedade sem um fator unificante, que forneça um conteúdo significado e o 
entrelace com as estruturas simbólicas. $\mathrm{O}$ que pode fazer isso, segundo o autor, é a criação imaginária própria da história, aquilo em que e pelo que a história se constitui. De nossa parte, podemos dizer que a violência, como um contingente próprio da história, vem marcada por criações imaginárias que não decorrem somente do uso da força física ou da motivação interna dos indivíduos, mas que se sustentam na e pela própria história das relações entre os sujeitos, suas condições de existência e a consciência que delas se tem.

\section{Referências}

CASTORIADIS, Cornelius. A instituição imaginária da sociedade. 6. ed. Rio de Janeiro: Paz e Terra, 1982.

FERREIRA, Aurélio Buarque de Holanda. Novo Aurélio Século XXI: o dicionário da língua portuguesa. 3. ed. Rio de Janeiro, Nova Fronteira, 1999. FONTINHA, Rodrigo. Novo Dicionário Etimológico da Língua Portuguesa. Porto: Domingos Barreira, s/d.

HOUAISS, Antonio, VILLAR, Mauro \& FRANCO, Francisco. Dicionário Houaiss da Língua Portuguesa. Rio de Janeiro: Objetiva, 2004.

OLIVEIRA, Sheila Elias de. Cidadania. História e política de uma palavra. Campinas, SP: Pontes, 2006.

PÊCHEUX, Michel. Análise Automática do Discurso (AAD-69). In: GADET, F. \& HAK, T. (orgs.) Por uma análise automática do discurso: uma introdução à obra de Michel Pêcheux. 3. ed. Campinas, SP: Editora da Unicamp, 1997. 